Pacific Journal of Mathematics

ON THE UNIQUE DETERMINATION OF SOLUTIONS OF THE 


\title{
ON THE UNIQUE DETERMINATION OF SOLUTIONS OF THE HEAT EQUATION
}

\author{
W. FULKS
}

1. Introduction. Recently it has been shown independently by Hartman and Wintner [5] and by the present author [4] that if $u(x, t)$ has continuous derivatives $u_{x x}$ and $u_{t}$, and is a nonnegative solution of the heat equation

$$
u_{x x}(x, t)-u_{t}(x, t)=0
$$

in a rectangle $R:\{0<x<1 ; 0<t<k \leq \infty\}$, then $u(x, t)$ can be represented in the form

$$
\begin{array}{rl}
u(x, t)=\int_{0+}^{1-0} & G(x, t ; y, 0) d A(y) \\
& +\int_{0}^{t} G_{y}(x, t ; 0, s) d B(s)-\int_{0}^{t} G_{y}(x, t ; 1, s) d C(s),
\end{array}
$$

where

$$
G(x, t ; y, s)=\frac{1}{2}\left[\vartheta_{3}\left(\frac{x-y}{2}, t-s\right)-\vartheta_{3}\left(\frac{x+y}{2}, t-s\right)\right],
$$

and where $\vartheta_{3}$ is the Jacobi theta function. The integrals are Riemann-Stieltjes integrals with nondecreasing integrator functions, $A, B$, and $C$. The first integral may be improper but is absolutely convergent. It was further shown (see [5] and [3]) that

$$
u(x, 0+)=A^{\prime}(x)
$$

and

$$
u(0+, t)=B^{\prime}(t-0) ; u(1-0, t)=C^{\prime}(t-0)
$$

at every point where the derivatives in question exist.

Received January 30, 1952. The preparation of this paper was sponsored, in part, by the Office of Naval Research, Contract Nonr-386(00).

Pacific J. Math. 3 (1953), 387-391 
2. Theorem. As to the question of the extent to which (4) and (5) uniquely determine $u(x, t)$, it is clear that they do not do so completely, for the singular solution $G_{y}(x, t ; 0,0)$, called a heat explosion by Doetsch [2], has normal boundary values identically zero on the three boundaries $x=0, x=1$, and $t=0$ of $R$. Yet $A, B, C$, through formula (2), do uniquely determine $u$; hence one might expect that by proper choice of the path of approach to the boundary, zero boundary values would assure the vanishing of $u$. In particular, because of the central role played by $G$ and $G_{y}$ in the representation (2), one might expect those paths to be the curves along which these functions become unbounded. This leads us to the following:

The OREm. Suppose

(a) $u(x, t)$ is a nonne gative solution of ( 1$)$ in $R$;

(b) $u_{x x}$ and $u_{t}$ are continuous in $R$;

(c) $u(x, 0+)=0$ $(0<x<1)$

(d) for every $s(0 \leq s<k), \lim u(x, t)=0$ as $(x, t)$ tends to $(0, s)$ along some parabolic arc of the form $t-s=a x^{2}, a>0$, and $\lim u(x, t)=0$ as $(x, t)$ tends to $(1, s)$ along some parabolic arc of the form $t-s=a(x-1)^{2}, a>0$.

Then $u(x, t) \equiv 0$ in $R$.

3. Proof. As we remarked in the first sentence, conditions (a) and (b) permit representation of $u$ in the form (2). From the formula

$$
\vartheta_{3}(x / 2, t)=(\pi t)^{-1 / 2} \sum_{n=-\infty}^{\infty} \exp \left[\frac{-(x+2 n)^{2}}{4 t}\right]
$$

which can be found in [2], it is easily seen that for $0<x<1$ the two latter integrals in formula ( 2$) \longrightarrow 0$ as $t \longrightarrow 0+$. Furthermore,

$$
\begin{aligned}
& \int_{0+}^{1-0} G(x, t ; y, 0) d A(y)=\int_{0+}^{\delta} G(x, t ; y, 0) d A(y) \\
& \quad+\int_{\delta}^{1-\delta} G(x, t ; y, 0) d A(y)+\int_{1-\delta}^{1-0} G(x, t ; y, 0) d A(y),
\end{aligned}
$$

where $\delta<(1 / 2) \min [x, 1-x]$ and is taken so small that, given $\epsilon>0$,

$$
\left|\int_{0+}^{\delta} G(x, t ; y, 0) d A(y)\right|<\epsilon \text { and }\left|\int_{1-\delta}^{1-0} G(x, t ; y, 0) d A(y)\right|<\epsilon
$$

uniformly in $t$, for $0<t \leq t_{0}$ for some $t_{0}$. Possibility to do this is ensured by [ 5 , 
Lemma 2, p. 385]. Now

$$
\begin{aligned}
\int_{\delta}^{1-\delta} G(x, t ; y, 0) d A(y)=\int_{\delta}^{1-\delta}(4 \pi t)^{-1 / 2} \exp \left[\frac{-(x-y)^{2}}{4 t}\right] d A(y) \\
+\int_{\delta}^{1-\delta} \sum_{\substack{n=-\infty \\
n \neq 0}}^{\infty}(4 \pi t)^{-1 / 2} \exp \left[\frac{-(x-y+2 n)^{2}}{4 t}\right] d A(y) \\
-\int_{\delta}^{1-\delta} \sum_{n=-\infty}^{\infty}(4 \pi t)^{-1 / 2} \exp \left[\frac{-(x+y+2 n)^{2}}{4 t}\right] d A(y) .
\end{aligned}
$$

The two latter integrals are easily seen to vanish with $t$. Since also the left side of $(2) \longrightarrow 0$ as $t \longrightarrow 0$, it follows that, if $\delta^{\prime}<\delta$,

$$
\begin{aligned}
\varlimsup_{t \rightarrow 0+} \int_{\delta^{\prime}}^{1-\delta^{\prime}}(4 \pi t)^{-1 / 2} \exp \left[\frac{-(x-y)^{2}}{4 t}\right] d A(y) \\
\quad \leq \varlimsup_{t \rightarrow 0+} \int_{\delta}^{1-\delta}(4 \pi t)^{-1 / 2} \exp \left[\frac{-(x-y)^{2}}{4 t}\right] d A(y) \leq 2 \epsilon .
\end{aligned}
$$

Let $\epsilon \longrightarrow 0$ and obtain

$$
\lim _{t \rightarrow 0+} \int_{\delta^{\prime}}^{1-\delta^{\prime}}(4 \pi t)^{-1 / 2} \exp \left[\frac{-(y-x)^{2}}{4 t}\right] d A(y)=0 .
$$

By [6,Th.7], we see that $A(y)$ is constant between $\delta^{\prime}$, and $1-\delta^{\prime}$. Let $\delta^{\prime} \rightarrow 0$. This ensures the vanishing of the first integral of (2).

Now let us turn to the boundary $x=0$. Suppose that for some $t_{0}$ the boundary function $B(s)$ is not continuous. If $\sigma$ is the jump (positive since $B(s)$ is increasing) in $B(s)$ at $s=t_{0}$, then for $t>t_{0}$, since $G_{y}(x, t ; 0, s) \geq 0$ ( see [ 5 , p. 370]).

$$
\begin{aligned}
u(x, t) & \geq \int_{0}^{t} G_{y}(x, t ; 0, s) d B(s) \geq \sigma G_{y}\left(x, t ; 0, t_{0}\right) \\
& =\frac{1}{2} \sigma x \pi^{-1 / 2}\left(t-t_{0}\right)^{-3 / 2} \exp \left[\frac{-x^{2}}{4\left(t-t_{0}\right)}\right] \\
& +\frac{1}{2} \sigma \pi^{-1 / 2}\left(t-t_{0}\right)^{-3 / 2} \sum_{\substack{n=-\infty \\
n \neq 0}}^{\infty}(2 n+x) \exp \left[\frac{-(2 n+x)^{2}}{4\left(t-t_{0}\right)}\right] .
\end{aligned}
$$


-Since $u(x, t) \longrightarrow 0$ as $(x, t) \longrightarrow\left(0, t_{0}\right)$ along $t-t_{0}=a x^{2}$ for some $a>0$, we have

$$
\begin{aligned}
& u(x, t) \geq \frac{1}{2} \sigma \pi^{-1 / 2} x^{-2} a^{-3 / 2} \exp \left[\frac{-1}{4 a}\right] \\
& +\frac{1}{2} \sigma \pi^{-1 / 2} a^{-3 / 2} \sum_{\substack{n=-\infty \\
n \neq 0}}^{\infty} \frac{2 n+x}{x^{3}} \exp \left[\frac{-(2 n+x)^{2}}{4 a x^{2}}\right],
\end{aligned}
$$

As $x \longrightarrow 0+$, the sum clearly $\longrightarrow 0$; but

$$
\lim _{(x, t) \rightarrow\left(0, t_{0}\right)} u(x, t)=0 \geq \frac{\lim _{x \rightarrow 0}}{2} \sigma \pi^{-1 / 2} x^{-2} a^{-3 / 2} \exp \left[\frac{-1}{4 a}\right]=\infty .
$$

This is a contradiction. Hence $\sigma=0$, and $B(s)$ is continuous for $0 \leq s<k$.

Now let $t=t_{0}+a x^{2}$. Then

$$
\begin{aligned}
u(x, t) \geq & \int_{t_{0}}^{t_{0}+a x^{2} / 2} G_{y}(x, t ; 0, s) d B(s) \\
= & \int_{t_{0}}^{t_{0}+a x^{2} / 2} \frac{1}{2} x \pi^{-1 / 2}(t-s)^{-3 / 2} \exp \left[\frac{-x^{2}}{4(t-s)}\right] d B(s) \\
& \quad+\int_{t_{0}}^{t_{0}+a x^{2} / 2} \frac{1}{2} \pi^{-1 / 2}(t-s)^{-3 / 2} Q(x, t ; s) d B(s),
\end{aligned}
$$

where

$$
Q(x, t ; s)=\sum_{\substack{n=-\infty \\ n \neq 0}}^{\infty}(2 n+x) \exp \left[\frac{-(2 n+x)^{2}}{4(t-s)}\right]
$$

Clearly the latter integral vanishes with $x$, Since in the interval of integration we have

$$
\exp \left[\frac{-x^{2}}{4(t-s)}\right] \geq \exp \left[\frac{-x^{2}}{4\left(a x^{2} / 2\right)}\right]=\exp \left[\frac{-1}{2 a}\right]
$$

and

$$
t-s \leq a x^{2}
$$


it follows that

$$
\begin{aligned}
u(x, t) & \geq \frac{1}{2} \pi^{-1 / 2} a^{-3 / 2} x^{-2} \exp \left[\frac{-1}{2 a}\right]\left[B\left(t_{0}+\frac{a x^{2}}{2}\right)-B\left(t_{0}\right)\right]+o(1) \\
& \geq K \frac{B\left(t_{0}+a x^{2} / 2\right)-B\left(t_{0}\right)}{a x^{2} / 2}+o(1)
\end{aligned}
$$

where $K$ is a positive constant. Letting $x \rightarrow 0$, we obtain

$$
0 \geq \varlimsup_{x \rightarrow 0} \frac{B\left(t_{0}+a x^{2} / 2\right)-B\left(t_{0}\right)}{a x^{2} / 2}=D^{+}\left[B\left(t_{0}\right)\right] .
$$

Hence, by $[1, \mathrm{p} .580], B(s)$ is a monotone decreasing function. Since it is nondecreasing, it must be constant. Similarly it can be shown that $C(s)$ is constant. This completes the proof.

It seems probable that conditions (b), (c) and (d) would ensure the vanishing of $u(x, t)$ if it were represented by (2) with $A, B, C$ of bounded variation, but the proof eludes the author.

\section{REFERENCES}

1. C. Caratheodory, Vorlesungen Über Reelle Funktionen, Berlin, 1927.

2. G. Doetsch, Theorie und Anwendung der Laplace-Transformation, New York, 1943.

3. W. Fulks, On the boundary values of solutions of the heat equation, Pacific J. Math. 2 (1952), 141-145.

4. - On integral representations and uniqueness of solutions of the heat equation, University of Minnesota Thesis, June, 1949.

5. P. Hartman and A. Wintner, On the solutions of the equation of heat conduction, American J. Math. 72 (1950), 367-395.

6. D. V. Widder, Positive temperatures on an infinite rod, Trans. Amer. Math. Soc. 55 (1944), 85-95.

The University of Minnesota 



\section{PACIFIC JOURNAL OF MATHEMATICS}

\section{EDITORS}

\section{R. U. FOEINSON}

University of California

Berkeley 4, California

E. HewitT

University of Washington

Seattle 5 , Washington
P. P. DILWOR TH

California Institute of Technology

Pasadena 4, California

E. F. BECKENBACH

University of California

Los Angeles 24, California

\section{ASSOCIATE EDITORS}

$\begin{array}{llll}\text { H. BUSEMANN } & \text { P. R. HALMOS } & \text { BØRGE JESSEN } & \text { J. J. STOKER } \\ \text { HERBERT FFDERER } & \text { IIEINZ HOPF } & \text { PAUL LÉVY } & \text { E. G. STRAUS } \\ \text { MARSHALL, IIALI } & \text { R. D. JAMES } & \text { GEORGE PÓLYA } & \text { KÖSAKU YOSIDA }\end{array}$

\section{SPONSORS}

UNIVERSITY OF BRITISH COLUMBIA

CALIFORNIA INSTITUTE OF TECHNOLOGY.

UNIVERSITY OF CAIJIFORNIA, BERKELEY

UNIVERSITY OF CAIJIFORNIA, DAVIS

UNIVERSITY OF CALIFORNIA, LOS ANGELES

UNIVERSITY OF CALIFORNI A, SANTA BARBARA

UNIVERSITY OF NEVADA

OREGON STATE COLLEGE

UNIVERSITY OF OREGON

\author{
UNIVERSITY OF SOU TIERN CALIFORNIA \\ STANFORD RESEARCH INSTITUTE \\ STANFORD UNIVERSITY \\ WASHINGTON STATE COLLEGE \\ UNIVERSITY OF WASHINGTON \\ AMERICAN MATHEMATICAL SOCIETY \\ NATIONAL BUREAU OF STANDARDS, \\ INSTITUTE FOR NUMERICAL ANALYSIS
}

Mathematical papers intended for publication in the Pacific Journal of Mathematics should be typewritten (double spaced), and the author should keep a complete copy. Manuscripts may be sent to any of the editors except Robinson, whose term expires with the completion of the present volume; they might also be sent to M.M. Schiffer, Stanford University, Stanford, California, who is succeeding Robinson. All other communications to the editors should be addressed to the managing editor, E. F. Beckenbach, at the address given above.

Authors are entitled to receive 100 free reprints of their published papers and may obtain additional copies at cost.

The Pacific Journal of Mathematics is published quarterly, in March, June, September, and December. The price per volume (4 numbers) is $\$ 8.00$; single issues, $\$ 2.50$. Special price to individual faculty members of supporting institutions and to individual members of the American Mathematical Society: $\$ 4.00$ per volume; single issues, $\$ 1.25$.

Subscriptions, orders for back numbers, and changes of address should be sent to the publishers, University of California Press, Berkeley 4, California.

Printed at Ann Arbor, Michigan. Entered as second class matter at the Post Office, Berkeley, California.

\section{UNIVERSITY OF CALIFORNIA PRESS • BERKELEY AND LOS ANGELES}




\section{Pacific Journal of Mathematics}

\section{Vol. 3, No. 2 \\ April, 1953}

William George Bade, An operational calculus for operators with spectrum

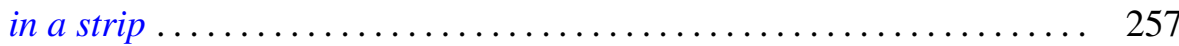

E. F. Beckenbach and Lloyd Kenneth Jackson, Subfunctions of several variables ..................................... 291

David Blackwell, Extension of a renewal theorem ................. 315

L. Carlitz, Some theorems on the Schur derivative ................ 321

Paul Arnold Clement, Generalized convexity and surfaces of negative curvature..................................... 333

Merrill M. Flood, On the Hitchcock distribution problem ............... 369

Watson Bryan Fulks, On the unique determination of solutions of the heat

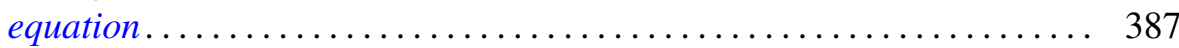

John W. Green, Length and area of a convex curve under affine transformation .................................... 393

William Gustin, An isoperimetric minimax .................. 403

Arthur Eugene Livingston, Some Hausdorff means which exhibit the Gibbs'

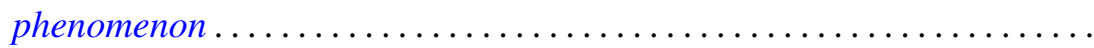

Charles Loewner, On generation of solutions of the biharmonic equation in the plane by conformal mappings ..................... 417

Gábor Szegő, Remark on the preceding paper of Charles Loewner ....... 437

Imanuel Marx and G. Piranian, Lipschitz functions of continuous

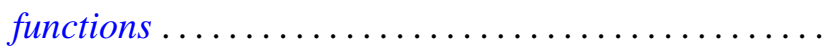

Ting-Kwan Pan, The spherical curvature of a hypersurface in Euclidean space ..

Ruth Lind Potter, On self-adjoint differential equations of second order ...

E. H. Rothe, A note on the Banach spaces of Calkin and Morrey...

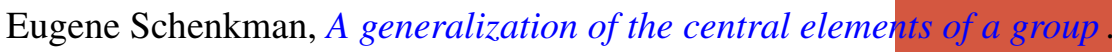

A. Seidenberg, A note on the dimension theory of rings .. . . 